\title{
Transient Stability Analysis of the Nigeria 330-kV Transmission Network
}

\section{Ignatius Kema Okakwu, Emmanuel Apoyi Ogujor}

Department of Electrical/Electronic Engineering, Faculty of Engineering, University of Benin, Benin City, Nigeria

Email address:

igokakwu@yahoo.com (I. K. Okakwu),emma.ogujor@uniben.edu (E. A. Ogujor)

\section{To cite this article:}

Ignatius Kema Okakwu, Emmanuel Apoyi Ogujor. Transient Stability Analysis of the Nigeria 330-kV Transmission Network. American Journal of Electrical Power and Energy Systems. Vol. 6, No. 6, 2017, pp. 79-87. doi: 10.11648/j.epes.20170606.11

Received: September 7, 2017; Accepted: September 26, 2017; Published: October 23, 2017

\begin{abstract}
Assessment of the dynamic response of generators, within a power system, when subjected to various disturbances, has been a major challenge to power system researchers and engineers for the past decades. This paper investigates the dynamic response of the generators in the Nigeria $330-\mathrm{kV}$ grid network when a balanced 3-phase fault is applied with the aim of determining the Critical Clearing Time (CCT) of the transmission network. The generalized swing equations for a multi-machine power system is presented. MATLAB software is employed as the tool for the simulations. A real network of Nigeria $330-\mathrm{kV}$ electric grid is used as a case study. The result obtained clearly show that there exist critical buses such as Benin, Onitsha and Jebba Transmission Station (TS) and critical transmission lines such as Benin-Olorunshogo Generating Station (GS) and Jebba TS-Shiroro GS within the network. The results also reveal that the system losses synchronism when a balanced 3-phase fault is applied to these identified critical buses and lines. The results further indicate that the Nigeria $330-\mathrm{kV}$ transmission network is on a red-alert, which requires urgent control measures with the aim of enhancing the stability margin of the network to avoid system collapse.
\end{abstract}

Keywords: Transient Stability, Critical Clearing Time, Nigeria 330-kV, Power System

\section{Introduction}

Recent studies show that electricity demand far outweighs generation due to increase in population, quest for development or industrialization. This increase in electricity demand could lead to negative effect on the power system security if not properly checked. Power system security indicates how secured is the power system under normal condition or with predicted contingencies. One of the major indices to assess the security of a power system is the transient stability [1]. Transient stability is the ability of power system to regain equilibrium after been subjected to disturbances. The system response to such disturbances involves large excursions of generator rotor angles, bus voltages, power flows and other systems variables/parameters. In transient stability assessment, the critical clearing time (CCT) is a very important parameter in assessing the stability of power system [2]. CCT is the maximum allowable time duration that a fault may occur in power system before losing synchronism. The fault clearing time (FCT) is set at random in a power system, hence, if the
FCT is more than CCT, the system losses synchronism. A robust power system is largely determined by its response to disturbances; therefore, a high value of CCT indicates a robust power system [3]. The Nigerian $330-\mathrm{kV}$ grid network is faced with series of challenges like voltage instability, long transmission lines, nature of transmission lines, high power losses [4], coupled with constant power demand increase and lack of sensitive equipment to detect and stabilize their challenges [5]. Due to inadequate transmission system, the system could be easily stressed, such that a relatively small disturbance can lead to total blackout or voltage collapse [6]. This paper, therefore, aims at investigating the transient stability assessment of the Nigeria $330-\mathrm{kV}$ transmission network for different fault location via the six geographical zones of the country. The remaining parts of the paper are organized as follows. Section 2 presents the mathematical formulation of the approach for a multi-machine power system. A brief description of the Nigerian 330-kV network is giving in section 3 . Section 4 presents the results and the discussion of the results obtained from the study while the study is concluded in section 5 . 


\section{Mathematical Formulation of Swing Equation for a Multi- Machine Power System}

Consider a multi-machine $n$-bus power network consisting of $m$ number of generators such that $n>m$. At any bus $i$ within the system, the complex voltages $\left(\mathrm{V}_{\mathrm{i}}\right)$, generators real power $\left(\mathrm{P}_{\mathrm{gi}}\right)$ and the generator reactive power $\left(\mathrm{Q}_{\mathrm{gi}}\right)$ can easily be obtained from the pre-fault load-flow analysis from which the initial machine voltages $\left(\mathrm{E}_{\mathrm{i}}\right)$ can also be obtained. This relationship can be expressed as

$$
E_{i}=V_{i}+j X_{i}\left[\frac{P_{g i}-j Q_{g i}}{V_{i}^{*}}\right]
$$

Where

$\mathrm{X}_{\mathrm{i}}$ is the equivalent reactance at bus $i$.

By converting each load bus into its equivalent constant admittance form, we have

$$
Y_{L i}=\frac{P_{L i}-j Q_{L j}}{\left|V_{i}\right|^{2}}
$$

Where $P_{L i}$ and $Q_{L i}$ are the respective equivalent real and reactive powers at each load buses.

The pre-fault bus admittance matrix $\left[Y_{b u s}\right]$ can therefore be formed with the inclusion of generators reactance and the converted load admittance. This can be partitioned as

$$
Y_{\text {bus }}=\left[\begin{array}{ll}
Y_{11} & Y_{12} \\
Y_{21} & Y_{22}
\end{array}\right]
$$

Where $Y_{11}, Y_{12}, \quad Y_{21}$ and $Y_{22}$, are the sub-matrices of $Y_{b u s}$. Out of these four sub-matrices, $Y_{11}$, whose dimension is $m \times m$ is the main interest of this paper as it contains generators buses only with the load buses eliminated.

Equation (3) is formulated for the network conditions such as pre-fault, during fault and post-fault. The $Y_{b u s}$ for the network is then formulated by eliminating all nodes except the internal generator nodes. The reduction is achieved based on the fact that injections at all load nodes are zero. The nodal equations, in compact form, can therefore be expressed as

$$
\left[\begin{array}{l}
1 \\
0
\end{array}\right]=\left[\begin{array}{ll}
Y_{m m} & Y_{m n} \\
Y_{n m} & Y_{n n}
\end{array}\right]\left[\begin{array}{l}
V_{m} \\
V_{n}
\end{array}\right]
$$

By expansion equation (4) can be expanded as

$$
\begin{array}{r}
I_{m}=Y_{m m} V_{m}+Y_{m n} V_{n} \\
\text { And } 0=Y_{n m} V_{m}+Y_{n n} V_{n}
\end{array}
$$

By combining equations (5) and (6) and some mathematical manipulations, the desired reduced admittance matrix can be obtained as

$$
Y_{\text {reduced }}=Y_{m m}-Y_{m n} Y_{n n}^{-1} Y_{n m}
$$

$\mathrm{Y}_{\text {reduced }}$ is the desired reduced matrix with dimension $\mathrm{m} \times \mathrm{m}$, where $\mathrm{m}$ is the number of generators.

The electrical power output of each machine can then be written as

$$
\mathrm{P}_{\mathrm{ei}}=\mathrm{E}_{\mathrm{i}}^{2} Y_{i i} \cos \theta_{i i}+\sum_{\substack{i=1 \\ j \neq i}}^{m}\left|E_{i}\right|\left|E_{j}\right|\left|Y_{i j}\right| \operatorname{Cos}\left(\theta_{i j}-\delta_{i}+\delta_{j}\right)
$$

Equation (8) is then used to determine the system during $\begin{array}{lllll}\text { fault } & \mathrm{P}_{\mathrm{ei}} & \left(P_{\text {ei(during-fault })}\right) \text { and post-fault } & \mathrm{P}_{\mathrm{ei}} & \left(P_{e i(\text { post-fault })}\right)\end{array}$ conditions

The rotor dynamics, representing the swing equation, at any bus $i$, is given by

$$
\frac{H_{i}}{\pi f_{o}} \frac{d^{2} \delta_{i}}{d t^{2}}+D_{i} \frac{d_{i}}{d t}=P_{m i}-P_{e i}
$$

All the parameters retain their usual meanings.

Consider a case when there is no damping i.e. $D_{i}=0$, equation (9) can be re-written as

$$
\frac{H_{i}}{\pi f_{o}} \frac{d^{2} \delta_{i}}{d t^{2}}=P_{m i}-\left(\mathrm{E}_{\mathrm{i}}^{2} Y_{i i} \cos \theta_{i i}+\sum_{\substack{i=1 \\ j \neq i}}^{m}\left|E_{i}\right|\left|E_{j}\right|\left|Y_{i j}\right| \operatorname{Cos}\left(\theta_{i j}-\delta_{i}+\delta_{j}\right)\right)
$$

The swing equation for the during-fault condition can easily be expressed as

$$
\frac{H_{i}}{\pi f_{o}} \frac{d^{2} \delta_{i}}{d t^{2}}=P_{m i}-P_{e i(\text { during-faul })}
$$

Similarly, the swing equation for the post fault condition can be written as

$$
\frac{H_{i}}{\pi f_{o}} \frac{d^{2} \delta_{i}}{d t^{2}}=P_{m i}-P_{e i(\text { post }- \text { fault })}
$$

\section{The Nigeria 330-kV Transmission Network}

The Nigeria 330-kV transmission network used as the case study in this paper is shown in figure 1. It consists of eleven (11) generators, twenty one (21) load buses and thirty six (36) transmission lines, which cut across the six (6) Geopolitical zone (South-West, South-South, South-East, NorthCentral, North-West and North-East Region) of the country with long radial interconnected transmission lines as depicted in figure 2 . 


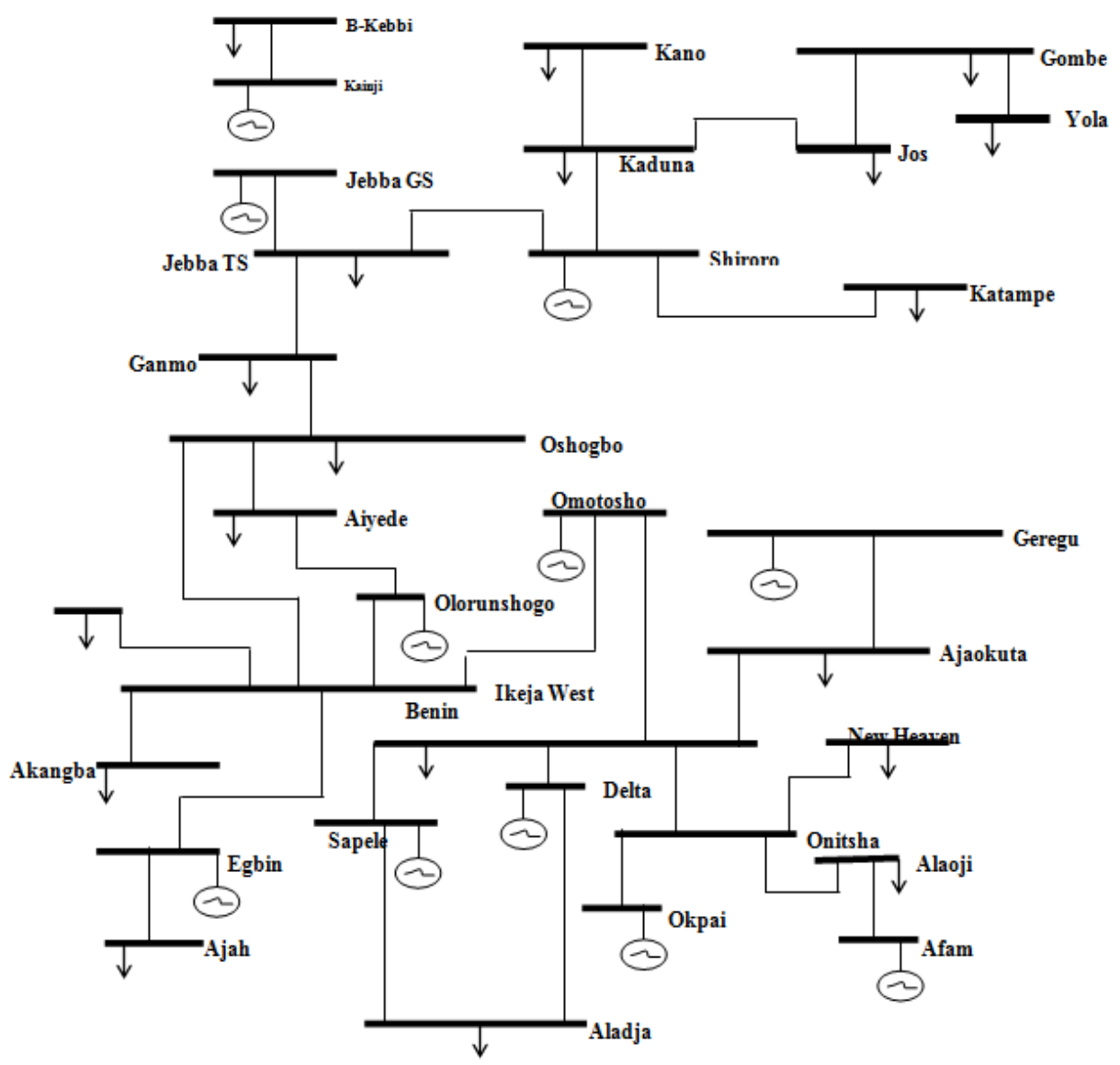

Figure 1. Single line diagram of the Nigeria $330 \mathrm{kV}$ transmission network.

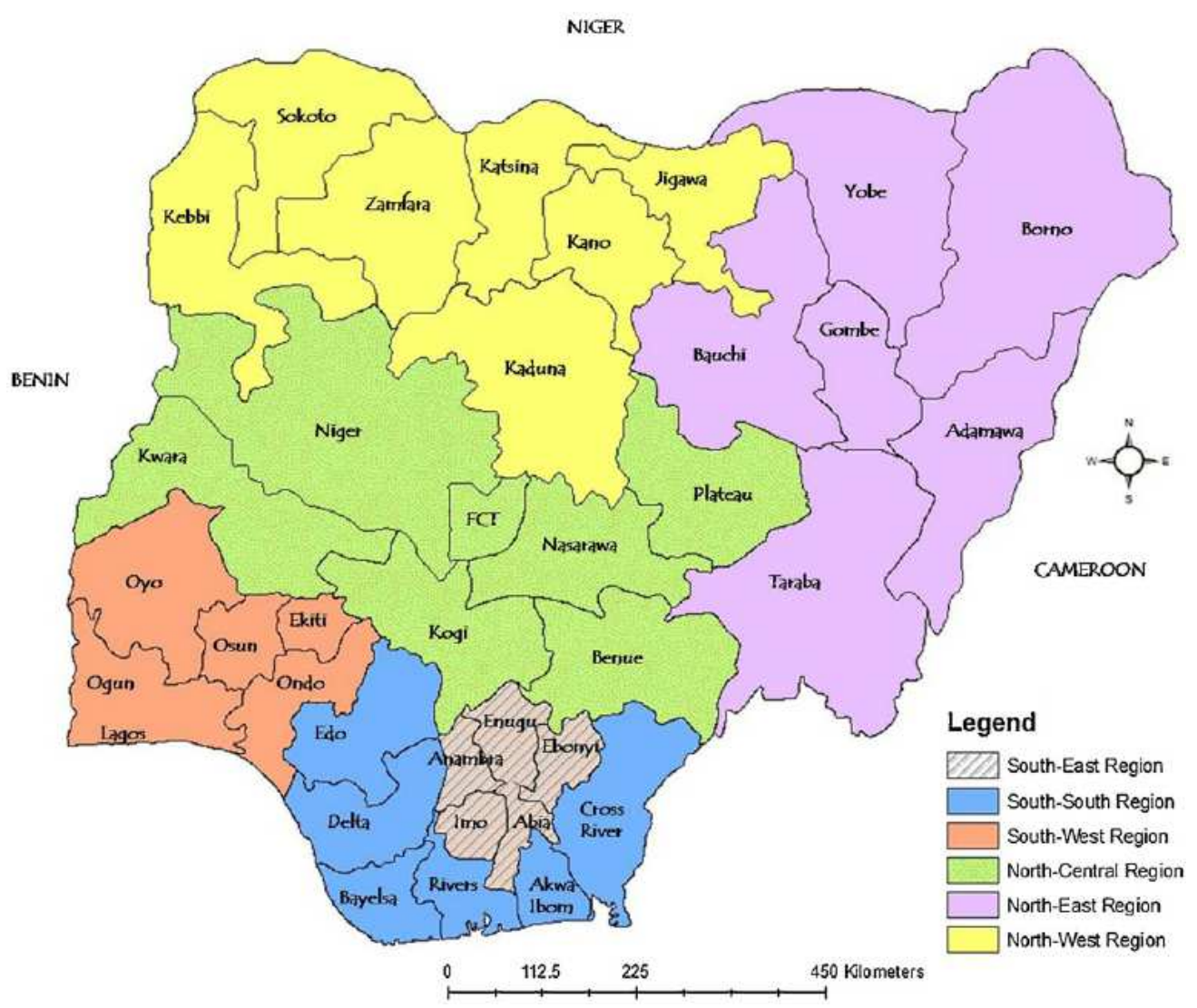

Figure 2. Map showing the six geo-political zone of Nigeria. 


\section{Results and Discussion}

The results obtained from the simulation are presented in this section. The simulation results are carried out on the MATLAB environment. The demonstration for the transient stability analysis on the Nigeria $330-\mathrm{kV}$ grid network, in this paper, considered six scenarios. These scenarios are created based on the six geo-political zones of Nigeria as shown in figure 2. A 3-phase fault was created at each of the six locations and the swing equations are solved to obtain the network conditions for both during-fault and post-fault numerical solver ODE45. A numerical solver, ODE45, which is a built-in MATLAB function, is employed in solving the $m$ number of swing equations within the system

Scenario 1: Fault on Bus 16 (South-West Region)

In this scenario, a three-phase fault was created on Aiyede bus (Bus 16) located in the South-West region with line 16-2 (aiyede-olorunshogo) removed. Figure 3 and 4 shows the dynamics responses of the generators for CCT of $840 \mathrm{~ms}$ and $850 \mathrm{~ms}$ respectively. The result shows that the generator at Afam generating station is the most critically disturbed. The system losses synchronism at a CCT of $850 \mathrm{~ms}$, which shows that for the system to remain stable, fault on Bus 16 must be cleared at $840 \mathrm{~ms}$, hence, the system will loss synchronism with the Generator at Afam mostly affected.

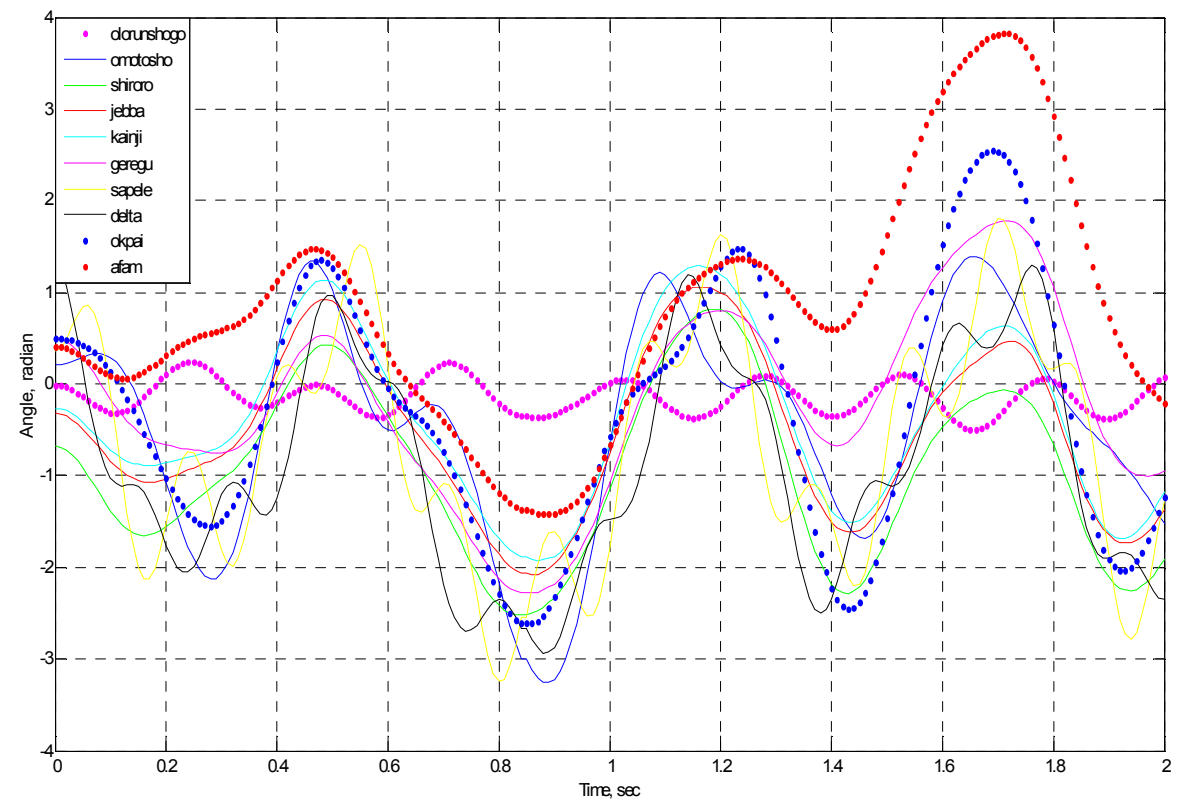

Figure 3. Rotor angle for a Three-phase fault on Bus 16, with Line 16-2 Removed(CCT=840ms).

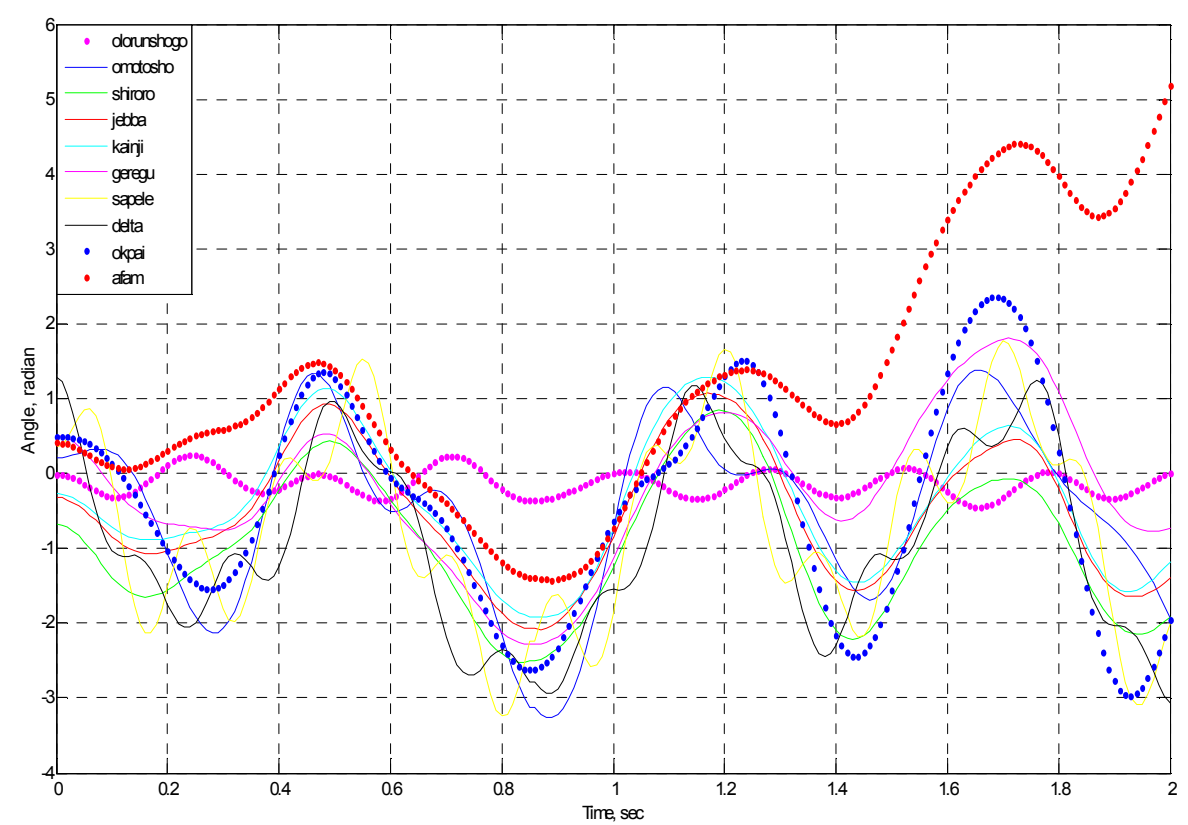

Figure 4. Rotor angle for a Three-phase fault on Bus 16, with Line 16-2 Removed(CCT=850ms). 
Scenerio 2: Fault on Bus 12 (South-South Region)

A three-phase fault created on Benin bus (Bus 12) located in the South-South Region with line 12-28(Benin-onitsha) removed. Figure 5 shows the dynamics responses of the generators for a CCT of $1.0 \mathrm{~ms}$. The result shows that all the generators, except the generator at Olorunshogo generating station loss synchronism. Hence, a 3-phase fault on Bus 12 of any duration will always cause loss of synchronism to all generators except Olorunshogo generating station.

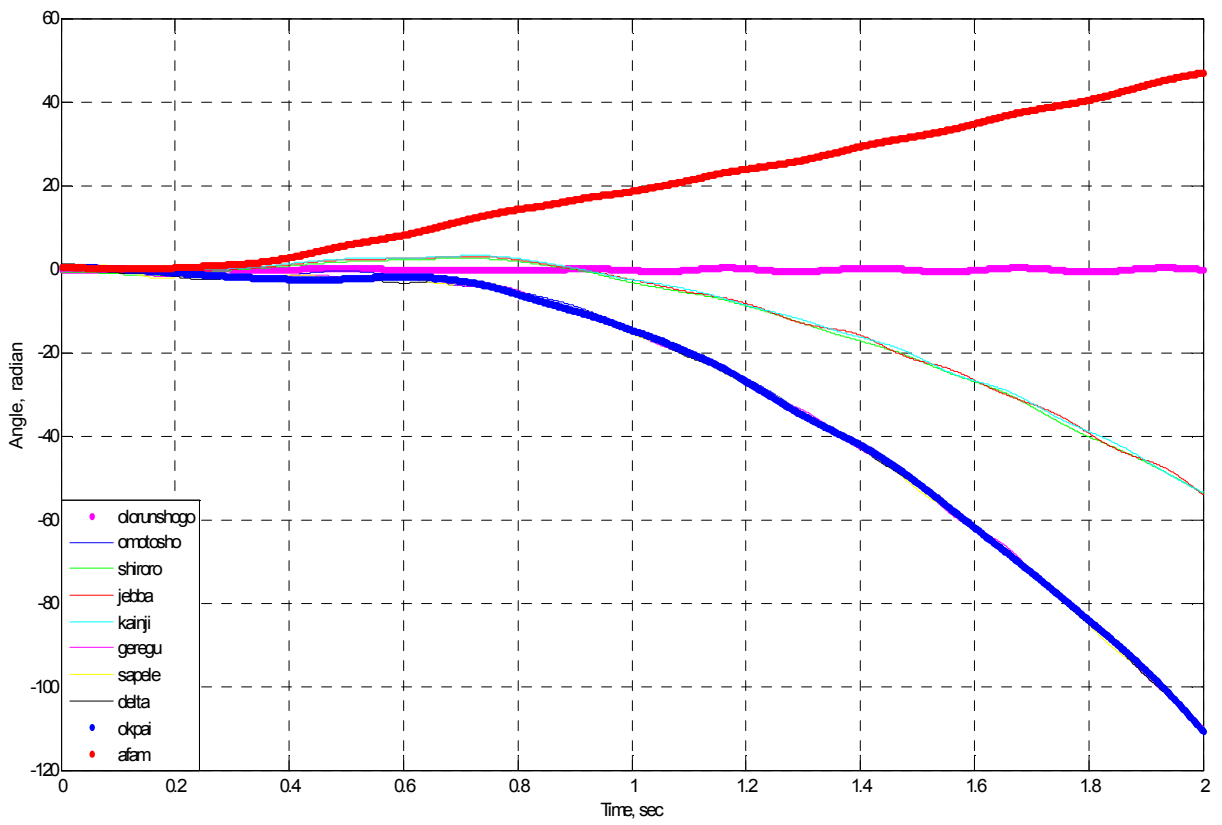

Figure 5. Rotor angle for a Three-phase fault on Bus 12, with Line 12-28 Removed (CCT = 1ms).

Scenario 3: Fault on Bus 28 (South-East Region)

Figure 6 shows that a 3-phase fault located in the South-East Region on Onitsha bus (Bus 28) of any duration will always cause instability because of all the generators loss synchronism except the one in Olorunshogo generating station.

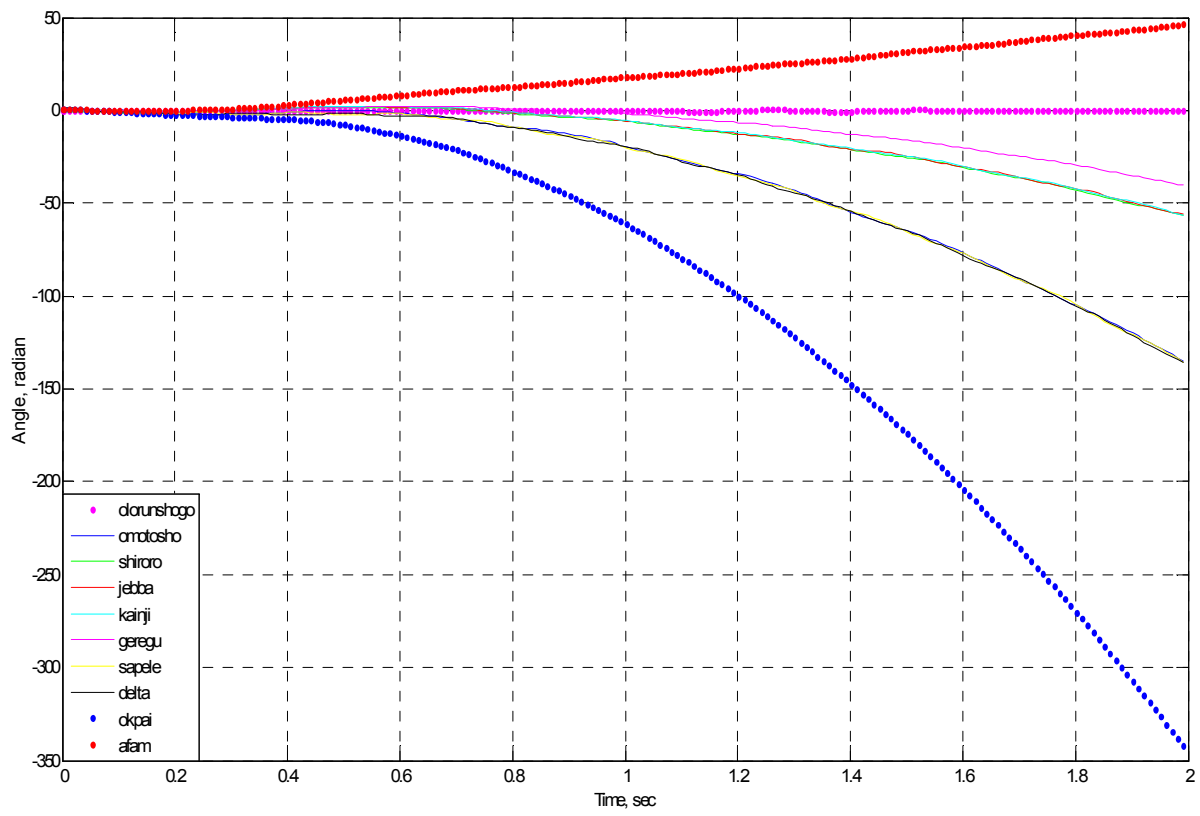

Figure 6. Rotor angle for a Three-phase fault on Bus 28, with Line 28-10 Removed(CCT =1ms).

Scenario 4: Fault on Bus 19 (North-Central Region)

Also, Figure 7 shows that a 3-phase fault of any duration location at Jebba TS (Bus 19) will always result to instability as the 
generators at Jebba and Shiroro generating stations always loss synchronism.

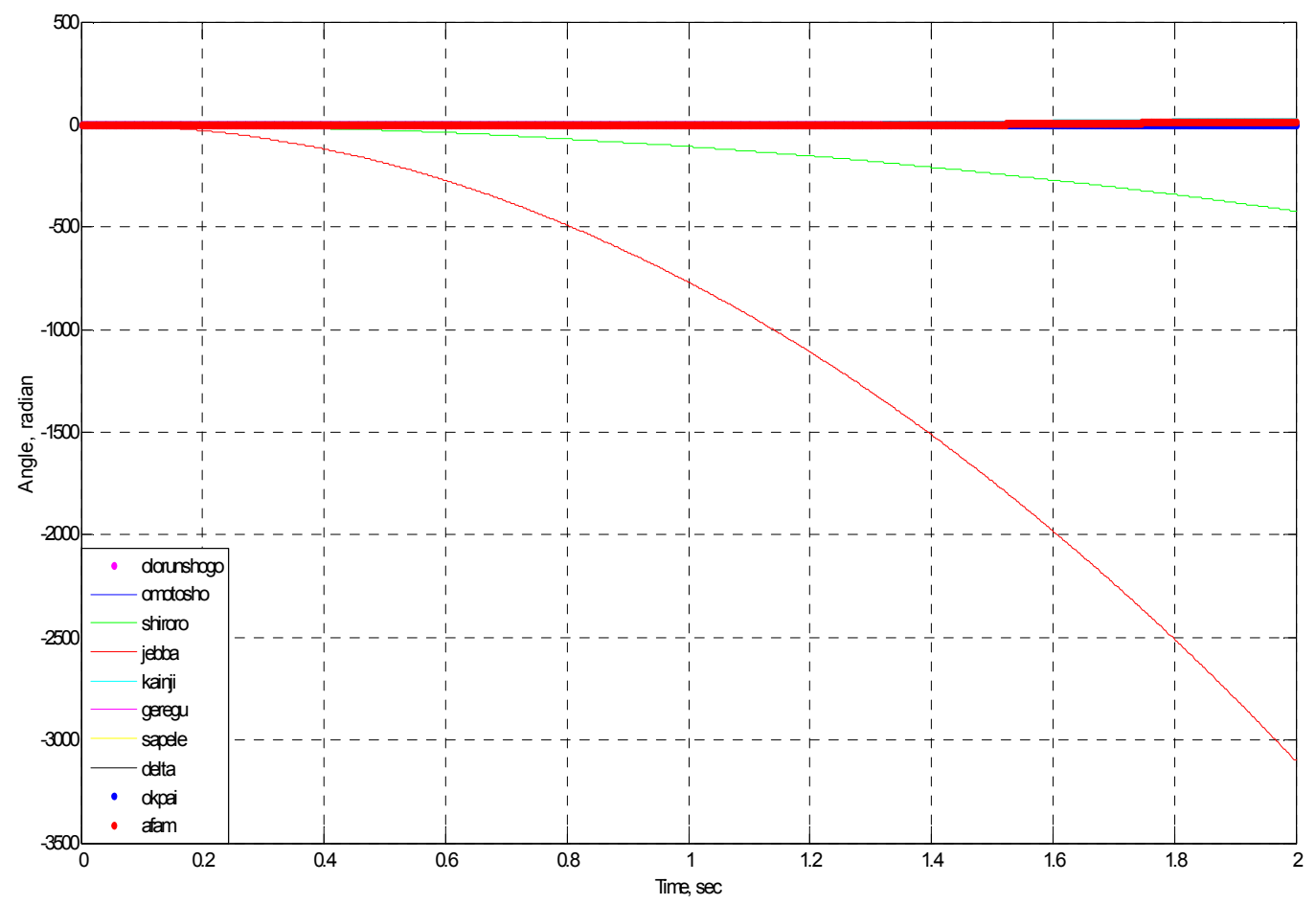

Figure 7. Rotor angle for a Three-phase fault on Bus 19, with Line 19-5 Removed(CCT=1ms).

Scenario 5: Fault on Bus 22 (North-West Region)

Figure 8 and 9 shows the dynamics responses of the generators when a 3-phase fault is located on Kaduna bus (located in the North-Central Region of Nigeria). The result shows that the CCT is $304 \mathrm{~ms}$ before the generator at Afam loss synchronism at $305 \mathrm{~ms}$.

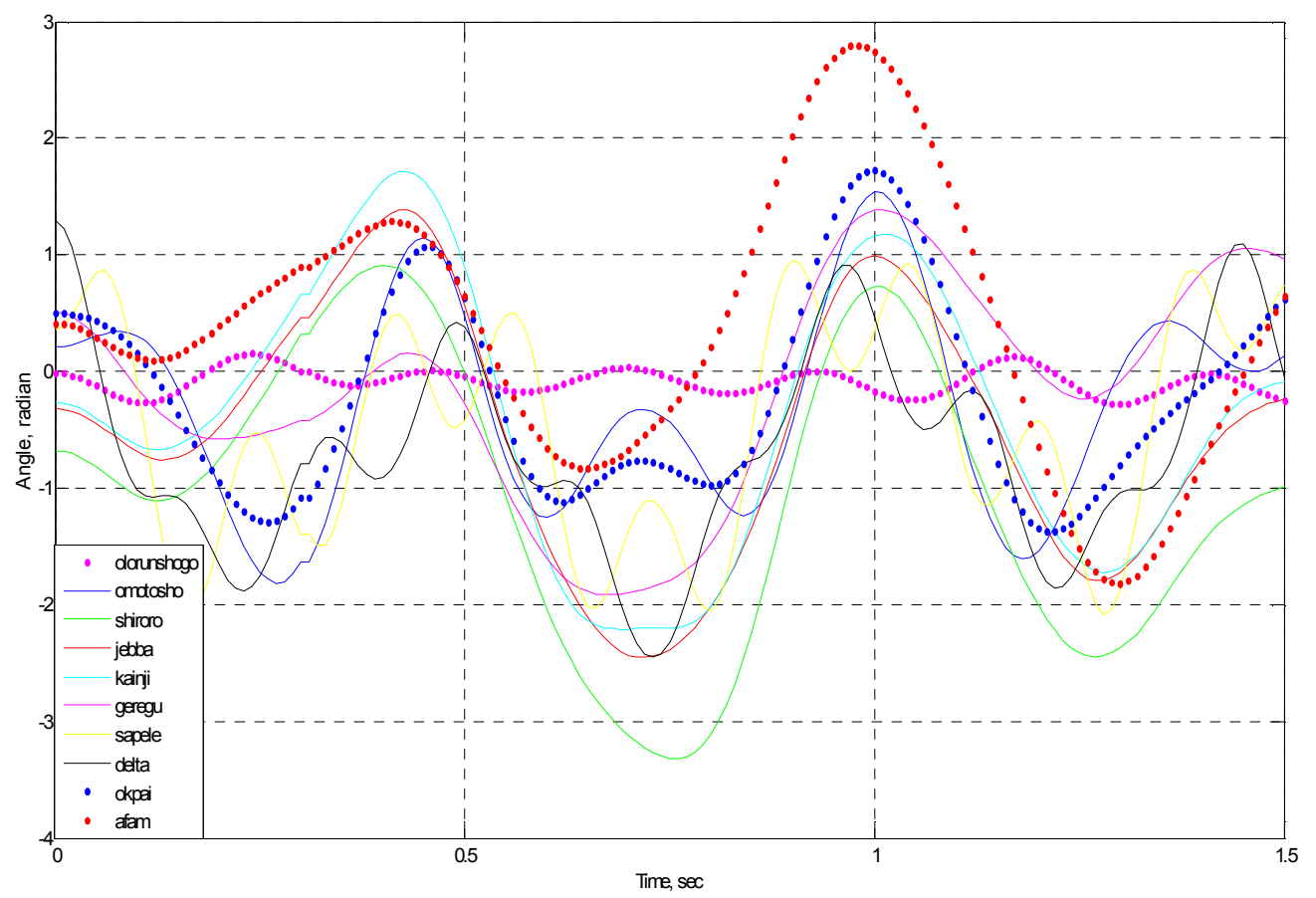

Figure 8. Rotor angle for a Three-phase fault on Bus 22, with Line 22-4 Removed (CCT =304ms). 


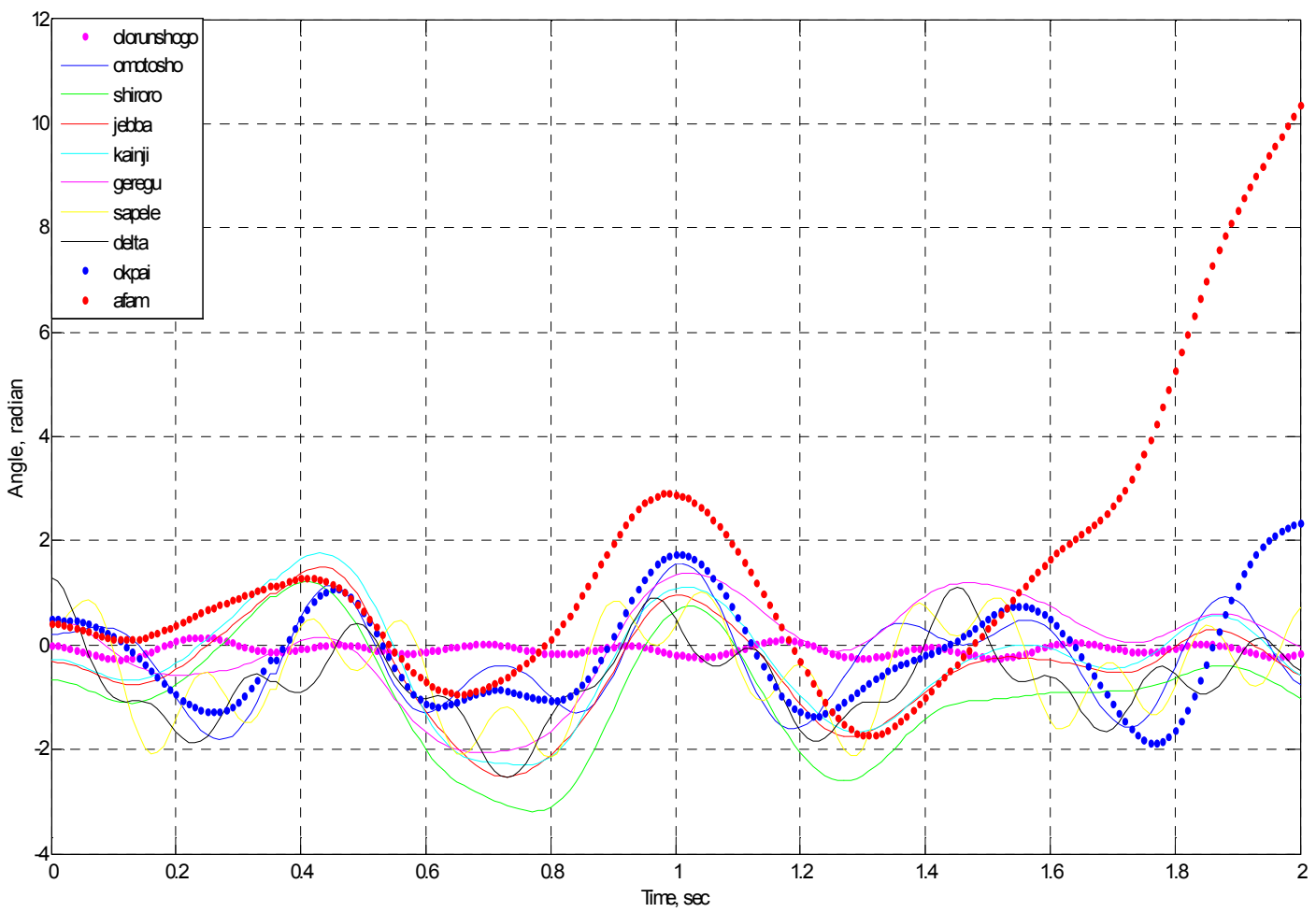

Figure 9. Rotor angle for a Three-phase fault on Bus 22, with Line 22-4 Removed (CCT =305ms).

Scenario 6: Fault on Bus 24 (North-East Region)

Lastly, Figure 10 and 11 shows the dynamics of the generators when a 3-phase fault located at the North-East Region (Gombe bus). The result reveals a CCT of $560 \mathrm{~ms}$ before the generator at Afam also loss synchronism at $561 \mathrm{~ms}$.

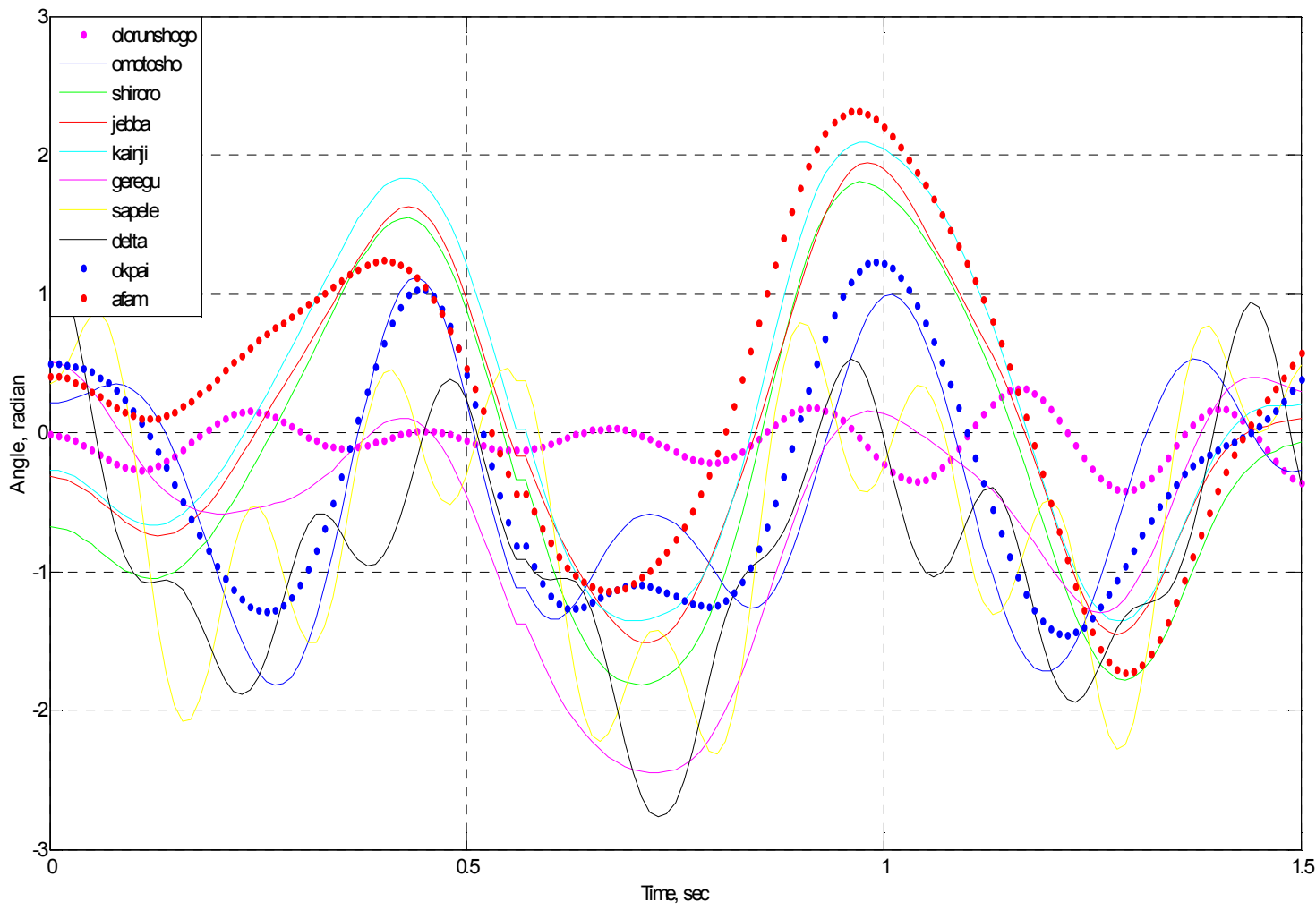

Figure 10. Rotor angle for a Three-phase fault on Bus 24, with Line 24-23 Removed(CCT $=560 \mathrm{~ms})$. 


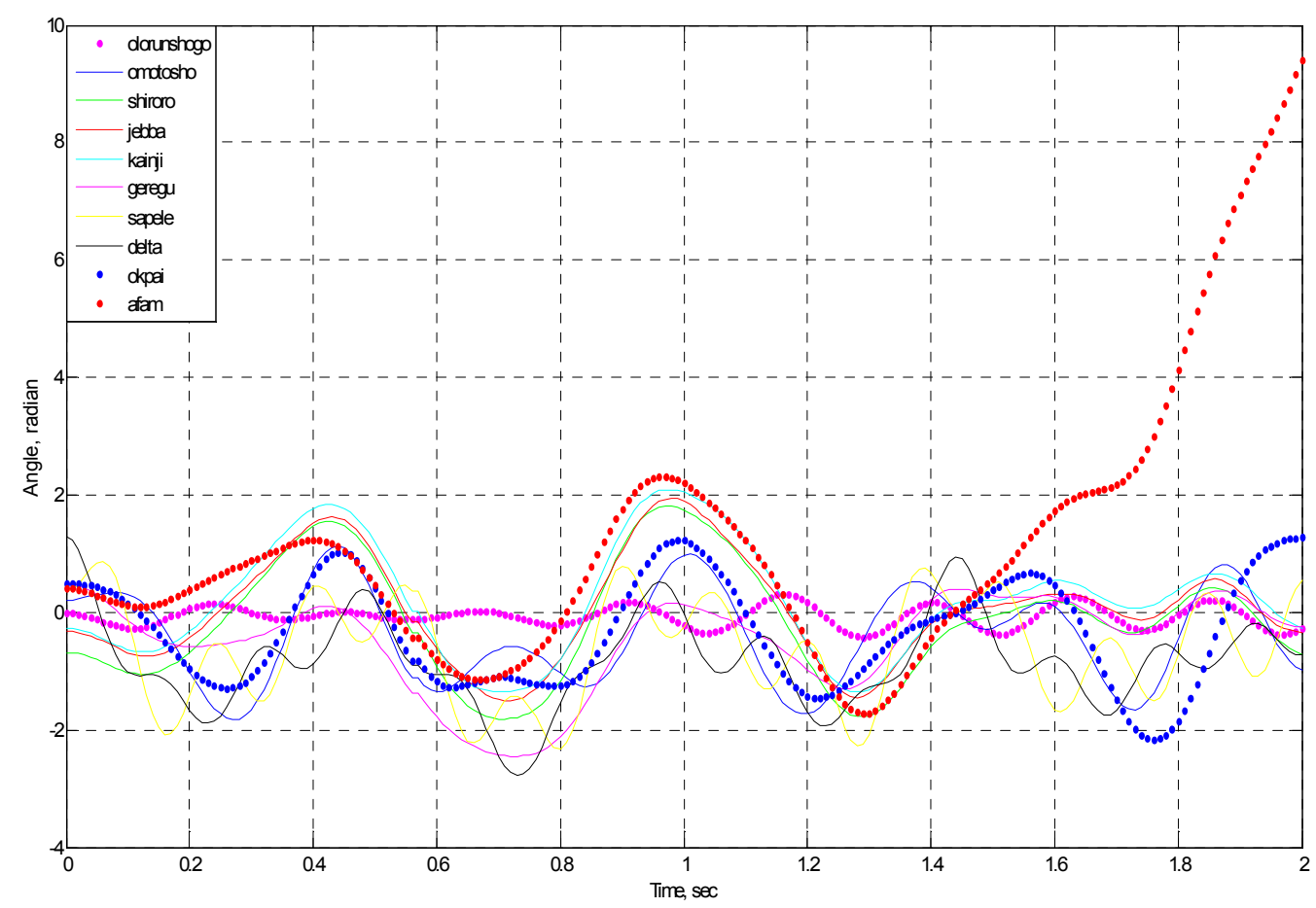

Figure 11. Rotor angle for a Three-phase fault on Bus 24, with Line 24-23 Removed(CCT = 561 $\mathrm{ms})$.

Table 1. Critical clearing time when a 3-phase fault occur.

\begin{tabular}{lllll}
\hline Scenerio No & Fault locations & Bus Region & Lines Removed & CCT (ms) \\
\hline 1 & Aiyede & South-West & Aiyede-Olorunshogo & 840 \\
2 & Benin & South-South & Benin-Onitsha & - \\
3 & Onitsha & South-East & Onitsha-Benin & - \\
4 & Jebba TS & North-Central & Jebba TS-Jebba GS & - \\
5 & Kaduna & North-West & Kaduna-Shiroro & 304 \\
6 & Gombe & North-East & Gombe-Jos & 560 \\
\hline
\end{tabular}

\section{Conclusion}

In this paper, transient stability analysis of the Nigeria $330-\mathrm{kV}$ grid system has been carried out. The mathematical formulations for the analysis are presented. The location of a balanced 3-phase fault, at various nodes, was determined based on the geo-political zones within the network. The dynamic responses for various fault locations are obtained. The results obtained show that the Nigeria $330-\mathrm{kV}$ transmission network is presently operating on a time-bomb alert state which could lead to total blackout if a 3-phase fault occurs on some strategic buses. The result obtained shows that when a 3-phase fault of any duration occurs on Benin, Onitsha or Jebba TS bus, the system losses synchronism immediately. Also, Benin-Onitsha and Jebba TS-Shiroro transmission lines have been identified as critical lines that can excite instability in the power network if removed to clear a 3-phase fault. This study will therefore recommend measures that will improve transient stability like the incorporation of FACTS devices into the transmission network, use of fast acting circuit breakers, use of breaking resistors at generator buses, short circuit current limiters, etc to avoid total system collapse, if a 3-phase fault occurs on the aforementioned critical buses or transmission lines.

\section{References}

[1] T. R. Ayodele, A. S. O. Ogunjuyigba, and O. O. Oladele, "Improving the Transient Stability of Nigerian $330 \mathrm{kV}$ Transmission Network using SVC", Nigeria Journal of Technology, pp. 155-166, 2016.

[2] P. R. Sharma, and Hooda, "Transient Stability Analysis of Power System using MATLAB", International Journal of Engineering Sciences and Research Technology, pp. 418-422, 2012.

[3] K. Karthikeyan, and P. K. Dhal, "Transient Stability Enhancement by Optimal location and tuning of STATCOM using PSO", Smart and Grid Technologies (ELSEVEIR), pp. 340-351, 2015.

[4] O. Eseosa, and F. O. Odiase, "Efficiency Improvement of Nigeria 330kV Network using FACTS devices", International Journal of Advances in Engineering and Technology, pp. 2641, 2012.

[5] O. Eseosa, and S. O. Onahaebi, "Optimal location of IPFC in Nigeria $330 \mathrm{kV}$ Integrated Power Network using GA Technique", Journal of Electrical and Electronics Systems, pp. $1-8,2015$. 
[6] P. O. Oluseyi, T. S. Adelaja, and T. O. Akinbulire, "Analysis of the Transient Stability Limit of Nigeria's $330 \mathrm{kV}$ Transmission sub-network", Nigeria Journal of Technology, pp. 213-226, 2017.

[7] F. I. Izuegbunem, C. B. Ubah AND I. O. Akwukwaegbu, "Dynamic security assessment of $330 \mathrm{kV}$ Nigeria power system", Academic Research International Journal, pp. 456466, 2012.

[8] S. O. Sanni, J. O. Haruna, B. Jimoh and U. O. Aliyu, "An analysis of transient stability enhancement capability of UPFC in a multi-machine power system", FUOYE Journal of Engineering Technology, pp. 48-54, 2016.

[9] N. Masood, A. Hassan and A. Chowohury, "Enchancement of real power transfer capability of transmission line", Journal of Energy and Power Engineering, pp. 1114-1118, 2012.

[10] M. N. Nwohu, A. Isah, A. U. Usman and A. A. Sadiq, "Optimal placement of thyristor controlled series compensator (TCSC) on Nigerian $330 \mathrm{kV}$ transmission grid to minimize real power losses", International Journal of Research Studies in Electrical and Electronics Engineering, pp. 18-26, 2016. 